\title{
Method to compare $\mu$-tensile bond strength of a self-etching adhesive and $\mu$-cohesive strength of adjacent dentin
}

\author{
José C. de la Macorra*, Adriana San-Nicolás
}

Department of Restorative Dentistry, Faculty of Odontology, Complutense University, 28040 Madrid, Spain

Received 15 July 2003; received in revised form 27 September 2004; accepted 16 November 2004

\author{
KEYWORDS \\ Micro-tensile bond \\ strength; \\ Micro-cohesive dentin \\ strength; \\ Self-etch adhesive; \\ Dentin
}

\begin{abstract}
Summary Laboratory results from tensile or micro-tensile testing of adhesive/ restorative systems need a gold standard to make their interpretation possible. This can be done by comparing the $\mu$-tensile bond strength ( $\mu$ TBS) of the tested adhesive(s) with the $\mu$-tensile cohesive strength ( $\mu \mathrm{TCS}$ ) of the adjacent dentin, which is meant to be replaced by the restoration.

Objectives. To test immediate $\mu$ TBS of an adhesive/restorative system versus $\mu$ TCS of the dentin adjacent to the bonded interface, in perfused specimens.

Methods. Enamel and roots of five-third sound molars were removed and teeth were perfused $\left(30 \mathrm{~cm}\right.$ distilled $\mathrm{H}_{2} \mathrm{O}$ ) until after the bonding procedure was completed. Parallel grooves $(1.5-\mathrm{mm}$ wide $\times 1.5-\mathrm{mm}$ deep, separated by $1.5 \mathrm{~mm})$, were drilled in the exposed dentin, under water refrigeration. Teeth were restored (AdheSE/Filtek Z250). Specimens were sawn from grooves to test $\mu$ TBS $(n=30)$ and from between grooves to test $\mu$ TCS $(n=32)$ of dentin, adjacent to adhesive interfaces, both areas to be tested at the same relative depth. Areas to be studied were rounded (mean bonded surface area for both groups, BA=0.68 $\mathrm{mm}^{2}$ ), and $\mu$ TBS and $\mu$ TCS were found. As not all BAs were identical, residuals of $\mu$ TBS and $\mu$ TCS values to the regression line relating $B A$ and tensile test results (representing the null hypothesis, i.e. $\mu \mathrm{TBS}=\mu \mathrm{TCS}$ ) were compared using a non-parametric test.

Results. Difference in the means of residuals was not statistically significant (two tails $p=0.067$ ).

Significance. mean $\mu$ TBS of the tested adhesive was not different to mean $\mu$ TCS of adjacent dentine. The null hypothesis was not rejected.

(C) 2005 Academy of Dental Materials. Published by Elsevier Ltd. All rights reserved.
\end{abstract}

\footnotetext{
${ }^{*}$ Corresponding author. Tel.: +34 913941996; fax: +34 913941999.

E-mail address: macorra@odon.ucm.es (J.C. de la Macorra).
}

\section{Introduction}

The determination of bond strength of dental adhesives to hard dental tissues is a matter of importance, in accordance with the great changes that adhesive techniques have produced in 
dentistry [1]. Usually, this bond strength is determined measuring the tensile or shear load at failure [2] between the adhesive and the substrate, divided by the cross-sectional area (BA) of the bonded interface to be tested [3].

In vitro tensile bond strength (TBS) results are influenced by a high number of variables $[2,4-9]$, including: time elapsed from extraction until the measuring procedure starts, tooth type (carious/ sound, young/adult, erupted/unerupted) and pretreatment (storing medium and time, temperature), their handling (perfusion yes/no, wetness) during and after (mechanical/thermal cycling, embedding) testing, tooth origin (human/animal), depth and location of interface, mechanical characteristics of the restorative material used, type of test (tensile, shear-pure or push-out-, micro-tensile, micro-shear), its stress rate, and specimen design, largely BA range and shape.

This variability originates great scattering in results obtained in different laboratories [4,8, $10,11]$, making necessary a standardization of bonding tests. However, total standardization of a bonding test seems problematical because not all laboratories would have the same facilities, use the same type of specimens, and follow the same protocols.

A reasonable alternative is to define a gold standard, a consensus value for comparison. This gold standard should represent an ideal or, at least, desirable TBS level that could be universally acceptable. If such a value could be established, it could become possible to level TBS values from different laboratories against it.

Many of the problems in comparing results from different laboratories come from testing adhesive restorative systems used on dentin. In this situation, an ideal material would theoretically be one that produces a bonded interface having comparable properties to the ones of the dentin it is replacing. In other words, TBS of the adhesive interface should, ideally, be as close as possible to the cohesive strength (CS) of the dentin it is substituting.

Actually, value of this gold standard is not universal because the CS of dentin also depends on the method used to measure it. Nevertheless, CS can be verified each time an adhesive is tested, under the same circumstances, in the same specimens and at the same or comparable location. In this way, the variable factors that depend on the research protocol and affect adhesion and cohesion testing, depending on each laboratory procedures, would influence both values (TBS and CS of dentin) simultaneously and the CS of dentin could be used as a gold standard.
Adhesive complex (one or more uneven layers of intact, demineralized and infiltrated dentin or enamel, of adhesive, and of restorative material, that are formed when adhesive procedures are undertaken) is not uniform [9]. It can have disruptions, gaps or air bubbles, and is formed over an irregular surface, the dentin or the enamel. This produces an irregular stress distribution [12]. When relatively large bonded areas (BAs) are used to test TBS of an adhesive interface, the probability of one or more disruptions being included in them is high, this disruptions then possibly acting as fracture initiators, causing low apparent TBS values $[9,13]$. If this is the case, results are lower than if smaller BAs would have been used. This would not be a major inconvenience if all laboratories would use the same BAs throughout their experiments, but this is far from happening.

To diminish this inconvenience, the microtensile bond strength ( $\mu$ TBS) test was developed [14]. When it was first used, BA ranged from 0.25 to $9 \mathrm{~mm}^{2}$ [15]. Since then, several studies have been published [16-24] that used BA of or around $1 \mathrm{~mm}^{2}$, resulting in an increase in published TBS results.

Furthermore, there are some studies [15,25-27] that show the relationship between BA and TBS to be somehow inversely related (Fig. 1). Mathematical description of their regression curves is shown in Table 1. The first of them [15] shows the relationship to be logarithmic, the second [25] to be linear, the third [26] to be inverse and the fourth [27] to be exponential. All of them show that smaller BAs bring out higher $\mu \mathrm{TBS}$, whatever the relation would be. And, with the exception of one of them [25], all show that this relation is not directly proportional: $\mu$ TBS value increases faster than BA decreases, when BA is close or below $1-\mathrm{mm}^{2}$. This makes the discrimination of BA critical when small testing areas (circa $1 \mathrm{~mm}^{2}$ ) are used.

In comparative studies, where BA will not be kept exactly constant for all specimens, there is then an intrinsic problem in comparing data within the study, which will cause distortion in the final results. Although BA means of all groups may be very similar or equal, this does not necessarily illustrate that it is identical for all samples. It may well happen that some of the specimens are tested using larger areas than others. And, as we have seen, minor differences in BA will, when areas around $1 \mathrm{~mm}^{2}$ are used, produce very high divergences in $\mu$ TBS results. In this situation, one or more groups may have an advantage when compared with others, because their apparent $\mu$ TBS results will be higher. 


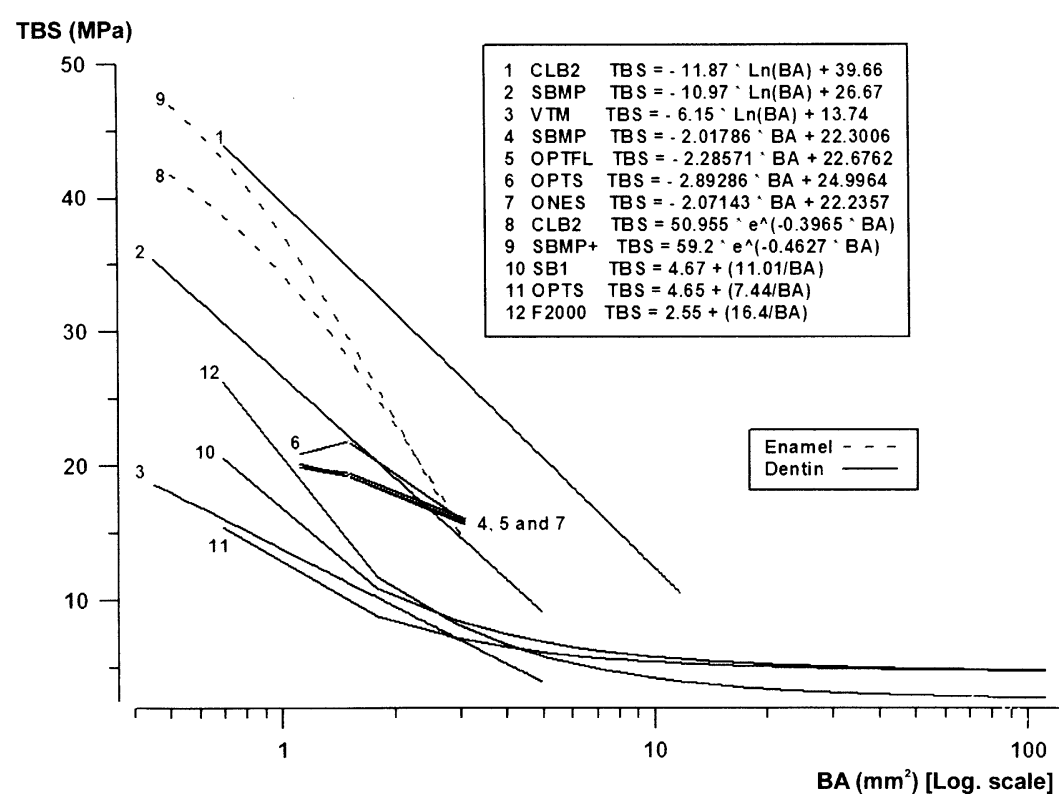

Figure 1 Previously described relationships between BA and TBS results. Note Logarithmic scale in BA axis.

One proposed solution to this $[16,28]$ is, using the least-squares means test, to adjust for the bonded area, before comparing bond strengths.

Regardless of what the mathematical expression is that will better describe the relationship between $\mathrm{BA}$ and $\mu \mathrm{TBS}$ in each experiment, this is usually calculated by the least-squares method. In this method, the total sum of the residuals (differences between the actual $\mu$ TBS value and the value predicted by the formula) is minimal or, if perfect adjustment is possible zero. These residuals are the distances from each individual sample results to the regression curve. Because of the calculation method, some of them are positive (i.e. $\mu$ TBS result for that case is higher than predicted) and some negative.

In this scenario, it can be assumed that the regression curve represents the behavior of all the materials that are being compared, as a group, whatever the individual BA is. Statistically, this line is the representation of the null hypothesis: if all specimens (of all materials) had the same $\mu$ TBS, all of then will be exactly located along the line.

In the simplest situation, when two materials' $\mu$ TBS (or a material's $\mu$ TBS and dentin's $\mu$ TCS, as in this report) are compared, if one of them has

Table 1 Previously published relationship among BA and TBS.

\begin{tabular}{|c|c|c|c|c|c|c|}
\hline \multirow[t]{2}{*}{ Authors } & \multirow[t]{2}{*}{ Material } & \multicolumn{2}{|c|}{ BA range } & \multirow[t]{2}{*}{ Proposed mathematical function } & \multirow[t]{2}{*}{ Substrate } & \multirow[t]{2}{*}{ Perfusion } \\
\hline & & $\operatorname{Max}$ & Min & & & \\
\hline Sano et al. [15] & $\begin{array}{l}\text { CLB2 }^{1} \\
\text { SBMP }^{2} \\
\text { VTM }^{3}\end{array}$ & $\begin{array}{r}11.65 \\
4.95 \\
4.95\end{array}$ & $\begin{array}{l}0.7 \\
0.45 \\
0.45\end{array}$ & $\begin{array}{l}\mathrm{TBS}=-11.87 \times \operatorname{Ln}(B A)+39.66 \\
\mathrm{TBS}=-10.97 \times \operatorname{Ln}(B A)+26.67 \\
\mathrm{TBS}=-6.15 \times \operatorname{Ln}(B A)+13.74\end{array}$ & Dentin & No \\
\hline $\begin{array}{l}\text { Prukkanon } \\
\text { et al. [25] }\end{array}$ & $\begin{array}{l}\text { SBMP }^{4} \\
\text { OPTFL }^{5} \\
\text { OPTS }^{6} \\
\text { ONES }^{7}\end{array}$ & 3.1 & 1.1 & $\begin{array}{l}\mathrm{TBS}=-2.01786 \times \mathrm{BA}+22.3006 \\
\mathrm{TBS}=-2.28571 \times \mathrm{BA}+22.6762 \\
\mathrm{TBS}=-2.89286 \times \mathrm{BA}+24.9964 \\
\mathrm{TBS}=-2.07143 \times \mathrm{BA}+22.2357\end{array}$ & & \\
\hline $\begin{array}{l}\text { Shono et al. } \\
{[27]}\end{array}$ & $\begin{array}{l}\mathrm{CLB}^{8} \\
\mathrm{SBMP}+{ }^{9}\end{array}$ & 3 & 0.5 & $\begin{array}{l}\mathrm{TBS}=50.955 \times \exp (-0.3965 \times \mathrm{BA}) \\
\mathrm{TBS}=59.2 \times \exp (-0.4627 \times \mathrm{BA})\end{array}$ & Enamel & \\
\hline $\begin{array}{l}\text { Macorra et al. } \\
{[26]}\end{array}$ & $\begin{array}{l}\text { SB1 } 1^{10} \\
\text { OPTS } \\
{\text { F } 2000^{12}}^{12} \\
\text { All }^{13}\end{array}$ & 110.86 & 0.69 & $\begin{array}{l}\mathrm{TBS}=4.67+(11.01 / \mathrm{BA}) \\
\mathrm{TBS}=4.65+(7.44 / \mathrm{BA}) \\
\mathrm{TBS}=2.55+(16.4 / \mathrm{BA}) \\
\mathrm{TBS}=4.17+(10.35 / \mathrm{BA})\end{array}$ & Dentin & Yes \\
\hline
\end{tabular}

BA, bonded area $\left(\mathrm{mm}^{2}\right)$; TBS; tensile bond strength (MPa); CLB2; clearfil liner bond 2; SBMP, ScotchBond multi-purpose; VTM, vitremer; OPTFL, optibond FL; OPTS, optibond solo; SBMP +, scotch bond multi-purpose plus; SB1, ScotchBond 1; Ln, natural logarithm; e, 27,183. Numbers in superscripts in the material's column identify each curve in Fig. 1. Numbers in the author's column identify references. 
a higher mean than the other, its results will, on average, be above the regression line, i.e. the mean of its residuals would be positive. The other's material residuals mean will be under the line, the mean of its residuals being negative.

Statistically, this means that the material with a positive residuals mean has higher results than it would have if the null hypothesis was true, and the second one has lower ones. In this way, comparing the means of the residuals for both materials with a simple test will easily and accurately test this hypothesis.

Objectives of this work are, first: to introduce and to test the micro-cohesive strength ( $\mu$ TCS) of dentin as a gold standard to level $\mu$ TBS of a current self-etching adhesive and, second: to test the hypothesis that the self-etching adhesive has similar $\mu$ TBS than $\mu$ TCS of adjacent dentin. (Null hypothesis, $\mu \mathrm{TBS}=\mu \mathrm{TCS}$ ).

\section{Material and methods}

Five-third lower molar teeth were sectioned (Exact $300 \mathrm{CP}$, Exact Apparatebau GmbH \& Co, Nordestedt, Germany) at occlusal and furcation level (Fig. 2A). The contents of the pulpal chamber were carefully removed with cotton and pliers. Apical aspects were bonded to methylmethacrylate cubes that allowed passing of two catheters into the closed pulpal chamber. These catheters were connected to a perfusion system, thus forming an artificial pulpal chamber that was completely filled, to fully rehydrate specimens. A constant pressure in the system $\left(30 \mathrm{~cm}\right.$ distilled $\left.\mathrm{H}_{2} \mathrm{O}\right)$ was maintained during the whole of preparation and bonding procedure.

An appropriate number of parallel grooves $(1.5 \mathrm{~mm}$ deep, $1.5 \mathrm{~mm}$ wide, with $1.5 \mathrm{~mm}$ of separation) was drilled, with constant abundant water-cooling, on the occlusal aspect (Fig. 2B).

The adhesive to be tested (AdheSE, Ivoclar Vivadent, Schaan, Liechtenstein, lot E35150) was applied and a resin composite (Filtek Z250, 3M ESPE, Seefeld, Germany, lot 2TF/A3) buildup was made (Fig. 2C) in two increments, one to fill grooves and a subsequent one to complete the buildup.

Specimens were vertically sectioned in two planes: parallel to the grooves and at $90^{\circ}$ to them (Fig. 2D), obtaining a variable number of compound rectangular sticks (dimensions $\approx 1.2 \times$ $1.2 \mathrm{~mm}$ ) from the grooves (to measure $\mu$ TBS) and from between the grooves (to measure $\mu \mathrm{TCS}$ ). All sticks were rounded to induce fracture at a similar relative depth, i.e. where the interface was placed

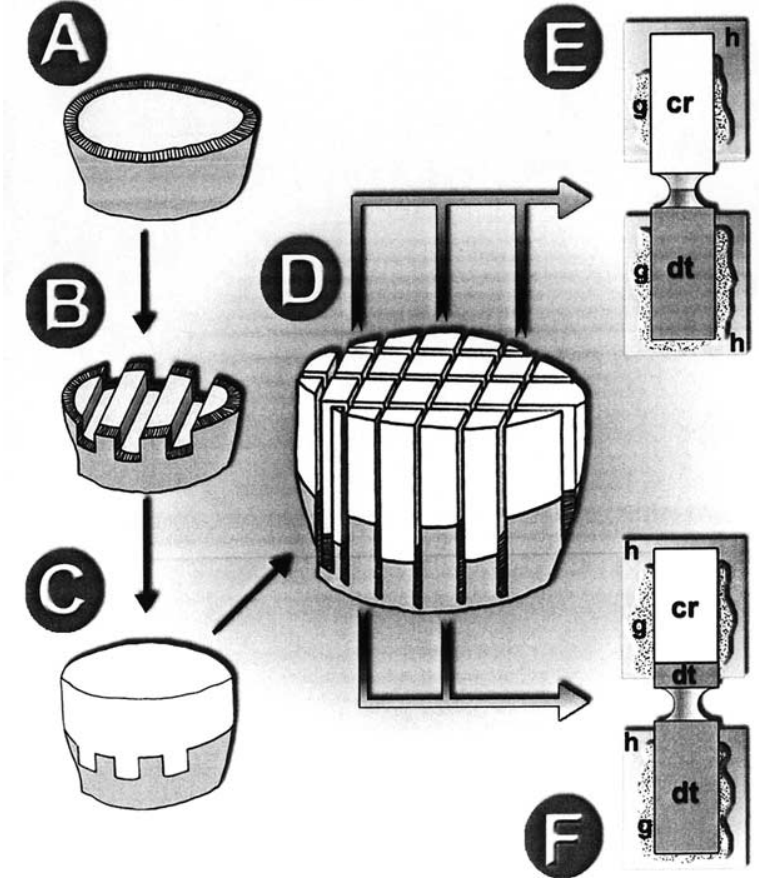

Figure 2 (A) Coronal and apical sectioning of specimen. (B) Grooves drilled in the occlusal aspect. (C) Composite buildup. (D) Two-planes specimen sectioning, parallel and perpendicular to grooves. (E) Glued rounded sticks from grooves to induce fracture at the interface level, to measure $\mu$ TBS. (F) Glued rounded sticks from between grooves to induce fracture at the same relative dept than in $\mathrm{E}$, to measure $\mu \mathrm{TCS}$. cr, composite resin; dt, dentin; g, glue; $h$, holder.

in the group obtained from the bottom of the grooves. The diameter at the site of induced fracture was measured (Mitutoyo Digital Caliper), in order to find the BA $\left(\mathrm{mm}^{2}\right)$.

Specimens were glued (Rocket, Dental Ventures of America, Corona, CA, USA) (Fig. 2, E-for $\mu$ TBSor $\mathrm{F}-$ for $\mu \mathrm{TCS}-)$ to a custom-made specimen holder. Vertical load at fracture $(\mathrm{N})$ was measured in a tensilometer (Hounsfield 500N, Croydon, England) at a crosshead speed of $1 \mathrm{~mm} / \mathrm{min}$, and $\mu$ TBS and $\mu \mathrm{TCS}$ were calculated $(\mathrm{MPa})$.

$\mu$ TBS and $\mu$ TCS results were related to their respective BAs (SPSS 11, Chicago, IL, USA) through a non-linear regression, with the least-squared method (Fig. 3). Residuals (MPa) of each actual case were stored in the variable 'distance'. The regression line was assumed to represent the null hypothesis, i.e. if all cases of both measurements had been identical, they would all had lain along this line.

As the dentin's source may have had an influence, this study separately tested if $\mu$ TBS and $\mu$ TCS results were homogeneous for different teeth. The Shapiro-Wilk test for normality was used to test if 


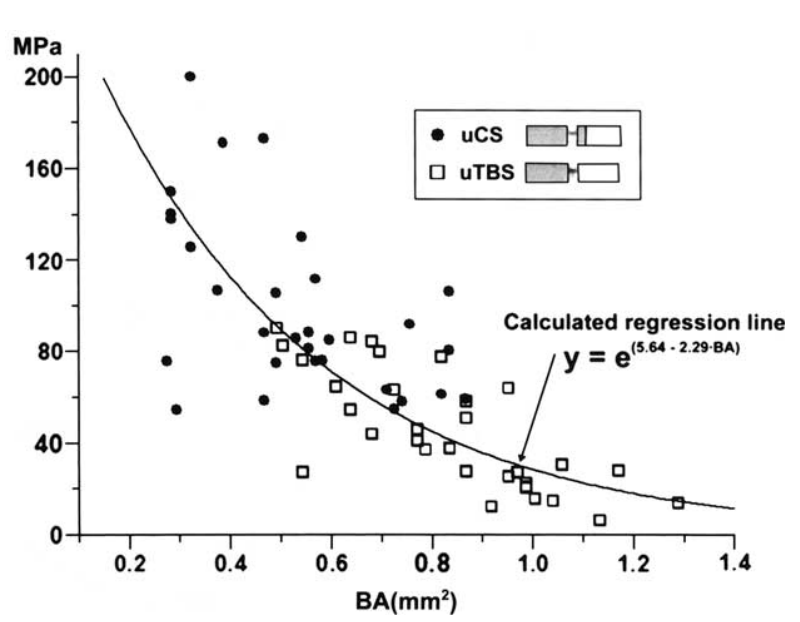

Figure 3 Experimental relationship between BA magnitude (in $\mathrm{mm}^{2}$ ) and $\mu$ TBS (empty squares, in $\mathrm{MPa}$ ) and $\mu$ TCS (filled circles, in MPa), and the corresponding calculated regression line.

$\mu$ TBS and $\mu$ TCS distances followed a normal distribution, and the ANOVA test was used to compare $\mu$ TBS and $\mu$ TCS of different sources, using tooth origin as the independent variable.

To test the null hypothesis, a Shapiro-Wilk normality test was applied to find out if the distribution of 'distance' values was normal in both $\mu$ TBS and $\mu$ TCS groups, and a two-tailed nonparametric Mann-Whitney $U$ comparison test was applied to test if the difference between the mean of distances ( $\mu$ TBS and $\mu$ TCS) was statistically significant.

\section{Results}

Results for BA, $\mu$ TBS, $\mu$ TCS and calculations of distances are shown in Table 2. One mean of distances ( $\mu \mathrm{TCS}, 9.02 \mathrm{MPa}$ ) was positive and the other one negative $(\mu \mathrm{TBS},-0.76 \mathrm{MPa})$, showing that groups are different. For each of them, specimens of the first are located, on average, over the common regression line and specimens of the second, below it.

It can be observed that the mean BA is higher in $\mu$ TBS specimens $\left(0.84 \mathrm{~mm}^{2}\right)$ than in $\mu$ TCS specimens $\left(0.53 \mathrm{~mm}^{2}\right)$. It was not possible (nor intended), in this experiment, to obtain exactly the same BA of all specimens, as this would have required very expensive equipment and more manipulations.

Standard deviation of the variable distance is relatively high, because the values are of the vertical distance in each case to the regression line, ignoring the distance from the line to zero at each point.

To test if tooth origin of specimens had an influence on results, we compared $\mu \mathrm{TCS}$ and $\mu \mathrm{TBS}$ means within teeth. ANOVA showed that differences were statistically not significant $(p=0.476$ and 0.339 , respectively). This supports the assumption that tooth origin had a negligible influence in this study.

Relating tensile test results (both $\mu \mathrm{TCS}$ and $\mu \mathrm{TBS}$ ) with their individual BAs with non-linear regression, results were: results $=\exp (5.64-2.29 \times \mathrm{BA})$, with an adjusted $r^{2}=0.63 \quad(p<0.00001)$. Regression explains $79 \%$ of the variation in tests results. From the graph the importance of considering BA can be seen, since $\mu$ TCS was calculated on specimens with smaller areas than the ones used to find $\mu$ TBS.

The Shapiro-Wilk test for normality of distribution of distances showed that $\mu$ TCS did show a normal distribution $(p=0.068)$, but $\mu$ TBS did not $(p=0.014)$. The Mann-Whitney $U$ comparison test results showed that the $\mu$ TCS mean distances and the $\mu$ TBS mean distances' difference $(9.02-0.76=$ 9.78) were not statistically significant (exact bilateral $p=0.067$ ).

\section{Discussion}

$\mu$ TBS and $\mu$ TCS were obtained, respectively, on specimens obtained from grooves and from between grooves prepared in dentin $(E$ and $F$ in Fig. 3, respectively). When the built-up composite resin was applied, grooves were filled up in the first increment. In subsequent increments the rest of the buildup was completed. This might have an influence on results, because the configuration factor for the bottom of the grooves, which supplies

Table 2 Results.

\begin{tabular}{|c|c|c|c|c|c|c|}
\hline & \multicolumn{3}{|c|}{ Dentin } & \multicolumn{3}{|c|}{ Adhesive } \\
\hline & BA & CS & Distance & BA & $\mu \mathrm{TBS}$ & Distance \\
\hline$n$ & 30 & & & 32 & & \\
\hline$m$ & 0.53 & 99.37 & 9.02 & 0.84 & 45.14 & -0.76 \\
\hline SD & 0.19 & 38.85 & 36.68 & 0.20 & 25.56 & 17.39 \\
\hline
\end{tabular}

$n$, number of cases; $m$, mean; SD, standard deviation; BA, bonded area $\left(\mathrm{mm}^{2}\right)$; CS, cohesive strength of dentin (MPa); $\mu$ TBS, microtensile bond strength $(\mathrm{MPa}$ ); distance, distance (in $\mathrm{MPa}$ ) from the actual case to the regression curve. 
specimens for $\mu$ TBS measurements, is higher than the one when buildup was completed and for the commonly used setup, where a flat dentin surface is used.

Specimens were obtained from perfused $(30 \mathrm{~cm}$ of distilled $\mathrm{H}_{2} \mathrm{O}$ ) specimens, and this perfusion was maintained during the drilling of grooves and the bonding procedure. It has been shown that perfusion has a detrimental effect on tensile test results of bonded interfaces $[7,29,30]$. In this instance, it seems not to have major consequences, because the adhesive/restorative combination tested has an acceptable behavior, in terms of these in vitro findings.

Specimens were rounded with a flame-shaped diamond bur. The rounded design of the BA was shown [25] to concentrate the stress at the narrowest part of the specimen, where the fracture was induced to move across the bonded interface, in $\mu$ TBS measurements. This stress will be evenly distributed from the circumference to the center of the bonded area.

Special attention was given to prepare the area to be tested at the same relative depth in both groups (bottom of grooves of $\mu$ TBS specimens). Due to the different composition of the area to be tested (adhesive interface or dentin), both groups of specimens were prepared resulting in distinct BAs, to avoid as much as possible premature or spontaneous fractures. Consequences are that mean BA was higher in the $\mu$ TBS specimens $\left(0.84 \mathrm{~mm}^{2}\right)$ than in the $\mu$ TCS specimens $\left(0.53 \mathrm{~mm}^{2}\right)$. This difference appeared because when $\mu$ TBS specimens were prepared, rounding of the interface was not as aggressive (range of BA: $1.29-0.49 \mathrm{~mm}^{2}$ ), as these specimens tend to split 'spontaneously' and fracture easily, probably because of the difference in stiffness between both sides of boundary. On the other hand, $\mu \mathrm{TCS}$ specimens could be rounded reaching a higher depth (range of BA: $0.87-0.27 \mathrm{~mm}^{2}$ ) because of their higher elasticity and homogeneity.

The best non-linear regression is obtained with the growth curve $\mu \mathrm{TBS}=\exp (5.64-2.29 \times \mathrm{BA})$. This regression explains $79 \%$ of the variation of tests results $(r=0.79)$. This type of relationship is different to others previously described [15,2527], where the relation had other mathematical formulations. In this study, a small range of BAs are used $\left(0.27-1.29 \mathrm{~mm}^{2}\right)$, forcing a very narrow window to define the relation. It is probable then, that if a wider BA range was used, mathematical expression of this relation would change.

The data in this study showed that the mean $\mu$ TCS (SD) is 99.37 (38.85) MPa (using areas ranging from 0.27 to $0.87 \mathrm{~mm}^{2}$ ), and the mean $\mu$ TBS (SD) is
45.14 (25.56) $\mathrm{MPa}$ with the BA ranging from 0.49 to $1.29 \mathrm{~mm}^{2}$. These data were not directly compared because $\mu$ TCS results (filled circles in Fig. 3 ) are superior to a greater extent because they were obtained from specimens where the prepared BA was smaller.

When distances to regression line for both $(\mu \mathrm{TBS}$ and $\mu \mathrm{TCS})$ groups are compared, their difference $(9.02-0.76=9.78 \mathrm{MPa})$ is not statistically significant (bilateral, two-tails, $p=0.067$ ). This means that the tested adhesive produces an adhesive interface that has a micro-tensile bond strength statistically not different to the micro-cohesive strength of adjacent dentin.

However, it is important to clarify the meaning of the statistical significance in this report. Although it could have been thought before the experiment that $\mu \mathrm{TCS}>\mu \mathrm{TBS}$, there were no data supporting this assumption. When this is the situation (to the authors' knowledge, there were no previous data on $\mu$ TBS and $\mu$ TCS in the same experiment), assumptions about which is the direction of the difference (about if $\mu \mathrm{TCS}>\mu \mathrm{TBS}$ or $\mu \mathrm{TCS}<\mu \mathrm{TBS}$ ) cannot be made, and the test has to be arranged two-tailed, bilateral. If the completely different hypothesis $\mu \mathrm{TCS}>\mu \mathrm{TBS}$ had been tested, something that can be made from this experiment (as it can now be assumed that $\mu \mathrm{TCS}>\mu \mathrm{TBS}$ ) significance would have been unilateral $(p=$ $0.067 / 2=0.034$ ), a radically different result.

Another possible way of relating results is calculating the predicted value for $B A=1 \mathrm{~mm}^{2}$ for both interfaces. This calculation results in $\mu \mathrm{TCS}_{1 \mathrm{~mm}}=37.5 \mathrm{MPa}$, and $\mu \mathrm{TBS}_{1 \mathrm{~mm}}=27.7 \mathrm{MPa}$. These would have (theoretically) been the results for both parameters if it had been possible to prepare all specimens with exactly $B A=1 \mathrm{~mm}^{2}$. To put it in other figures, the mechanical resistance of the adhesive/restorative system would have reached $74 \%$ of the cohesive strength of adjacent dentin if BA had constantly been $=1 \mathrm{~mm}^{2}$. The relevance of this level of difference still has to be found.

Table 3 shows CS values of previous publications. In these reports only mean BAs are cited, and it was not possible to know if all areas of all specimens throughout each report were the same. It can be seen that the predicted $\mu$ TCS results in this study for $1-\mathrm{mm}^{2}$ areas are lower than published. This difference could be caused by the storage method (specimens in the current study were kept in distilled water for up to a month before testing) or by the area where $\mu$ TCS was measured. Distance to pulpal chamber-remaining dentin thickness-is relatively low in this experiment, because it had to be at the same level as the bottom of the grooves, where $\mu$ TBS was measured. 
Table 3 CS of dentin values previously published.

\begin{tabular}{lll}
\hline Authors & Area used $\left(\mathrm{mm}^{2}\right)$ & CS $(\mathrm{MPa})$ \\
\hline Sano et al. [14] & 0.25 & 93.8 \\
Zhang et al. [31] & 0.275 & 20 \\
Carvalho et al. [32] & 0.5 & 57.6 \\
Bowen and & 0.97 & 52 \\
Rodriguez [33] & & \\
Lehman [34] & 1.37 & 41 \\
Liu et al. [35] & 1.5 & 83.93 \\
\hline
\end{tabular}

The proposed method for comparing results has some advantages. First, the dimensions of the bonded areas do not have to be exactly the same. This is impossible to achieve without complicatedand expensive-equipment and usually requires many specimen manipulations. Even more, this is sometimes undesirable if, for instance, research is designed to compare a brittle material as an adhesive substrate with a more elastic one. In this case, researchers may want to use bigger areas when testing the more rigid material than would be used with a more elastic one.

Second, this method makes it easier to compare results between different laboratories. Usually, results obtained in different laboratories have a considerable scatter due to different protocols of measurement. In this study, a gold standard was used: $\mu \mathrm{TCS}$ of dentin adjacent to the adhesive interface to be tested. All efforts were made to test dentin contiguous to the bonded interface, at the same relative depth. In this way, $\mu$ TBS results can be compared to a relevant measurement: microcohesive strength of dentin of the same teeth, at similar locations and with the same protocol, which is a good reference for what the tensile resistance of the bonded material should be. This comparison can be carried out directly, as in this study: finding the significance of the eventual differences of the means of distances to the common regression line, or by the percentage of $\mu$ TBS results into $\mu$ TCS of dentin. This would show what level reaches, in that specific laboratory, the tested adhesive(s).

\section{Conclusions}

The adhesive tested showed micro-tensile bond strength lower than micro-tensile cohesive strength of adjacent dentin, in perfused teeth, but this difference was not statistically significant.

The calculated micro-tensile strength of the adhesive/restorative system tested reached $73.8 \%$ of the cohesive strength of adjacent dentin, for bonded areas of $1-\mathrm{mm}^{2}$.

\section{Acknowledgements}

Dr F. Tay, of the University of Hong-Kong, made very valuable suggestions on the manuscript. This investigation is part of the $\mathrm{PhD}$ research of Dr A. San-Nicolás.

\section{References}

[1] Van Noort R. Principes de base de l'adhésion en dentisterie. Rev D'Odontostomatol 1995;24:257-71.

[2] Eliades G. Clinical relevance of the formulation and testing of dentin bonding systems. J Dent 1994;22:73-81.

[3] Lin CP, Chen RS, Liu CC, Lian SS. Failure criteria of dentinresin tensile bond test-a fracture mechanics approach. Scripta Mater 1998;38:115-21.

[4] Stanley HR. An urgent plea for standardized bonding (adhesion) testing. J Dent Res 1993;72:1362-3.

[5] Beech DR, Tyas MJ, Solomon A. Bond strength of restorative materials to human dentin: influence of post-extraction time. Dent Mater 1991;7:15-17.

[6] Takemori T, Chigira K, Hisamitsu H, Wakumoto S. Factors affecting tensile bond strength of composite to dentin. Dent Mater 1993;8:136-8.

[7] Al-Salehi SK, Burke FJT. Methods used in dentin bonding tests: an analysis of 50 investigations on bond strength. Quintessence Int 1997;28:717-23.

[8] Leloup G, D’Hoore W, Bouter D, Degrange M, Vreven J. Meta-analytical review of factors involved in dentin adherence. J Dent Res 2001;80:1605-14.

[9] Pashley DH, Sano H, Ciucchi B, Yoshiyama M, Carvalho R. Adhesion testing of dentin bonding agents: a review. Dent Mater 1995;11:117-25.

[10] Perdigao J, Lopes A. Dentin bonding-questions for the new milennium. J Adhes Dent 1999;1:191-209.

[11] Sudsangiam S, Van Noort R. Do dentin bond strength test serve a useful purpose? J Adhes Dent 1999;1:57-67.

[12] Van Noort R, Noroozi S, Howard IC, Cardew G. A critique of bond strength measurements. J Dent 1989;17:61-7.

[13] Mecholsky JJ. Fracture mechanics principles. Dent Mater 1995;11:111-2.

[14] Sano H, Ciucchi B, Matthews WG, Pashley DH. Tensile properties of mineralized and demineralized human and bovine dentin. J Dent Res 1994;73:1205-11.

[15] Sano H, Shono T, Sonoda H, Takatsu, Ciucchi B, Carvalho R, et al. Relationship between surface area for adhesion and tensile bond strength-evaluation of a micro-tensile test. Dent Mater 1994;10:236-40.

[16] Pashley DH, Carvalho R, Sano H, Nakajima M, Yoshiyama M, Shono $Y$, et al. The microtensile bond test: a review. $J$ Adhes Dent 1999;1:299-309.

[17] Harada N, Nakajima M, Pereira PNR, Yomaguchi S, Ogata M, Tagami J. Tensile bond strength of a newly developed one-bottle self-etching resin bonding system to various dental substrates. Dent Jpn 2000;36:47-53.

[18] Tay FR, Carvalho R, Sano H, Pashley DH. Effect of the smear-layers on the bonding of a self-etching primer to dentin. J Adhes Dent 2000;2:99-116.

[19] Hashimoto M, Ohno H, Endo K, Kaga M, Sano H, Oguchi H. The effect of hybrid layer thickness on bond strength: demineralized dentin zone of the hybrid layer. Dent Mater 2000;16:406-11. 
[20] Paul SS, Welter DA, Ghazi M, Pashley DH. Nanoleakage at the dentin-adhesive interface vs. tensile bond strength. Oper Dent 1999;24:181-8.

[21] Nakajima N, Sano H, Burrow MF, Tagami J, Yoshiyama M, Ebisu S, et al. Tensile bond strength and SEM evaluation of caries-affected dentin using dentin adhesives. J Dent Res 1995;74:1679-88.

[22] Nakajima N, Sano H, Urabe J, Tagami J, Pashley DH. Bond strengths of single-bottle dentin adhesives to cariesaffected dentin. Oper Dent 2000;25:2-10.

[23] Phrukkanon S, Burrow MF, Tyas MJ. The effect of dentine location and tubule orientation on the bond strengths between resin and dentine. J Dent 1999;27:265-74.

[24] Mak YF, Lai SCN, Cheung GSP, Chan AWK, Tay FR, Pashley DH. Micro-tensile bond testing of resin cements to dentin and an indirect resin composite. Dent Mater 2002;18:609-21.

[25] Prukkanon S, Burrow MF, Tyas MJ. Effect of cross-sectional surface area on bond strengths between resin and dentin. Dent Mater 1998;14:120-8.

[26] Escribano N, Del-Nero MO, de la Macorra JC. Inverse relationship between tensile bond strength and dimensions of bonded area. J Biomed Mater Res (Appl Biomat) 2003; 66B:419-24.

[27] Shono Y, Terashita M, Pashley EL, Brewer PD, Pashley DH. Effects of cross-sectional area on resin-enamel tensile bond strength. Dent Mater 1997;13:290-6.
[28] Shono Y, Ogawa T, Terashita M, Carvalho RM, Pashley EL, Pashley DH. Regional measurement of resin-dentin bonding as an array. J Dent Res 1999;78:699-705.

[29] Nikaido T, Burrow MF, Tagami J, Takatsu T. Effect of pulpal pressure on adhesion of resin composite to dentin: bovine serum versus saline. Quintessence Int 1995;26: 221-6.

[30] Eliades G. Clinical relevance of the formulation and testing of dentine bonding systems. J Dent 1994;22:73-81.

[31] Zhang Y, Agee K, Nör J, Carvalho R, Sachar B, Russell C, et al. Effects of acid-etching on the tensile properties of demineralized dentin matrix. Dent Mater 1998;14:222-8.

[32] Carvalho RM, Fernandes CAO, Villanueva R, Wang L, Pashley DH. Tensile strength of human dentin as a function of tubule orientation and density. J Adhes Dent 2001;3: 309-14.

[33] Bowen RL, Rodriguez MS. Tensile strength and modulus of elasticity of tooth structure and several restorative materials. J Am Dent Assoc 1962;64:378-87 [Cited by Sano et al. (1994)].

[34] Lehman ML. Tensile strength of human dentin. J Dent Res 1967;46:197-201.

[35] Liu J, Hattori M, Hasegawa K, Yoshinari M, Kawada E, Oda Y. Effect of tubule orientation and dentin location on the microtensile strength of bovine root dentin. Dent Mater $J$ 2002;21:73-82. 